\title{
Selective Activation of Corticotropin-Releasing Factor-2 Receptors on Neurochemically Identified Neurons in the Rat Dorsal Raphe Nucleus Reveals Dual Actions
}

\author{
Luise Pernar, ${ }^{1}$ Andre L. Curtis, ${ }^{1}$ Wylie W. Vale, ${ }^{2}$ Jean E. Rivier, ${ }^{2}$ and Rita J. Valentino ${ }^{1}$ \\ ${ }^{1}$ The Children's Hospital of Philadelphia, Philadelphia, Pennsylvania 19104, and ${ }^{2}$ The Salk Institute, La Jolla, California 92037
}

\begin{abstract}
The dorsal raphe (DR)-serotonin (5-HT) system has been implicated in stress-related psychiatric disorders. Stress may impact on this system through corticotropin-releasing factor (CRF), which densely innervates the DR. CRF binds to CRF-R1 and CRF-R2 receptors in the DR and has complex and opposing effects depending on the dose used and the endpoint examined. To clarify the impact of CRF on the DR-5-HT system, the effects of selectively activating CRF-R2 receptors (the predominant subtype) on extracellular DR neuronal activity were examined in halothane-anesthetized rats. Because the DR is neurochemically heterogeneous, when possible, neurons were labeled with neurobiotin for subsequent neurochemical classification as 5-HT or non-5-HT. Relatively low doses of urocortin II (UII) (0.1-10 ng) injected into the DR inhibited most $(79 \% ; n=34)$ neurons, whereas a higher dose $(30 \mathrm{ng})$ inhibited $28 \%$ and activated $41 \%(n=29)$. An analysis of effects on neurochemically identified neurons revealed that 5-HT neurons were inhibited by $0.1-10 \mathrm{ng}$ of UII and activated by $30 \mathrm{ng}$ of UII. Activation of 5-HT neurons by $30 \mathrm{ng}$ of UII likely resulted from disinhibition because the majority of non-5-HT neurons were inhibited by this dose. Antisauvagine-30, but not antalarmin, antagonized UII, implicating CRF-R2 receptors in the effects. The results suggest that activation of CRF-R2 on DR-5-HT neurons inhibits neuronal activity, whereas activation of CRF-R2 receptors on non-5-HT neurons may indirectly excite DR-5-HT neurons through disinhibition. Importantly, the tone of the DR-5-HT system can be regulated in a dynamic manner through CRF-R2 activation, being either decreased or increased depending on the level of endogenous or exogenous ligand.
\end{abstract}

Key words: urocortin II; serotonin; antalarmin; antisauvagine-30; stress; juxtacellular labeling; neurobiotin

\section{Introduction}

The dorsal raphe nucleus (DR), a major source of forebrainprojecting serotonin (5-HT) neurons, has been implicated in stress-related psychiatric disorders (Mann, 1999; Nutt, 2002). Stress has robust effects on the DR-5-HT system, increasing or decreasing 5-HT release in forebrain targets, depending on the stressor and region analyzed (Kirby et al., 1995; Adell et al., 1997; Kirby et al., 1997; Rueter et al., 1997). Stress-induced activation of DR neurons (indicated by c-fos expression) has been linked to behaviors that model affective disorders, such as learned helplessness and activity elicited by swim stress (Grahn et al., 1999; Roche et al., 2003). Cellular mechanisms involved in stress-induced regulation of the DR-5-HT system may underlie its role in stressrelated affective disorders.

Corticotropin-releasing factor (CRF) and related peptides

Received June 10, 2003; revised Dec. 15, 2003; accepted Dec. 17, 2003.

This work was supported by United States Public Health Service Grants MH58250 and MH02006 and a National Alliance for Research on Schizophrenia and Depression Distinguished Investigator Award (R.J.V.). We thank Dr. Kenner Rice for antalarmin, Dr. Patrice Guyenet for training in juxtacellular labeling, and Dr. Sheryl Beck for helpful comments on this manuscript. The expert technical assistance of Andrew Peoples is also acknowledged.

Correspondence should be addressed to Rita J.Valentino, The Children's Hospital of Philadelphia, 402C Abramson Pediatric Research Center, 34th Street and Civic Center Boulevard, Philadelphia, PA 19104. E-mail: valentino@email.chop.edu.

D0I:10.1523/JNEUROSCI.2885-03.2004

Copyright $\odot 2004$ Society for Neuroscience $\quad 0270-6474 / 04 / 241305-07 \$ 15.00 / 0$ mediate stress-induced regulation of the DR-5-HT system. CRF fibers innervate the DR (Valentino et al., 2001), and CRF receptors are highly expressed here (Chalmers et al., 1995). CRF alters DR neuronal activity in vivo (Kirby et al., 2000) and in vitro (Lowry et al., 2000) and 5-HT extracellular levels in DR targets (Linthorst et al., 1997; Kirby et al., 2000; Lowry et al., 2000; Price and Lucki, 2001; Price et al., 2002). Different effects of CRF on DR neuronal activity and 5-HT release have been reported, depending on the preparation (in vivo vs in vitro), site of administration, and region in which 5-HT release is measured. CRF activated a population of neurons in the caudal DR in vitro (Lowry et al., 2000). Consistent with this, evidence suggests that shockelicited CRF release in this region mediates 5-HT activation and the development of learned helplessness (Hammack et al., 2002). In contrast, bimodal effects of CRF on DR neuronal activity (in vivo) and forebrain 5-HT release have been reported, with low doses being inhibitory (Price et al., 1998; Kirby et al., 2000; Price and Lucki, 2001). Convergent findings suggest that inhibitory regulation of the DR-5-HT system by endogenous CRF is engaged during swim stress (Price et al., 2002; Roche et al., 2003). Several factors can account for the heterogeneous effects of CRF. The DR is composed of morphologically and neurochemically distinct neurons that differ in their neural connectivity (Molliver, 1987; Jacobs and Azmitia, 1992). CRF innervation of the DR is topographically organized, and CRF axon terminals in different 
DR subregions form different types of interactions (Valentino et al., 2001). Thus, CRF may affect different populations of neurons within the DR.

Two subtypes of CRF receptors (CRF-R1 and CRF-R2) are expressed in the DR. Ovine CRF (oCRF) and rat CRF ( $\mathrm{rCRF}$ ), the two CRF-like peptides that have been most examined, interact with both receptors. Because the CRF-R2 receptor is the most prevalent in the DR (Chalmers et al., 1995), this study characterized the effects of urocortin II (UII), a selective CRF-R2 agonist (Reyes et al., 2001), on extracellular DR neuronal activity in halothane-anesthetized rats. To address the possibility that CRF may have multiple effects that involve different neuronal phenotypes, neurons were labeled with neurobiotin and processed for immunohistochemical detection of 5-HT.

\section{Materials and Methods}

Subjects. Adult male Sprague Dawley rats (250-300 gm; Taconic Farms, Germantown, NY) were housed three per cage on a $12 \mathrm{hr}$ light/dark schedule in a temperature-controlled $\left(22^{\circ} \mathrm{C}\right)$ colony room. Rats were given ad libitum access to standard rat chow and water. Care and use of animals were approved by the Stokes Institute of the Children's Hospital of Philadelphia Institutional Animal Care and Use Committee and performed in accordance with the National Institutes of Health Guide for the Care and Use of Laboratory Animals. All efforts were made to minimize animal suffering, and only the minimum number of animals necessary to produce reliable scientific data were used.

Surgery and recording. Rats were anesthetized with a $1-2 \%$ halothanein-air mixture administered through a nose cone. Body temperature was monitored and maintained at $37^{\circ} \mathrm{C}$ with a homeothermic blanket control unit (Harvard Instruments, Cambridge, MA). The rats were positioned in a stereotaxic instrument with blunt ear bars with the head oriented at a $10^{\circ}$ angle to the horizontal plane (nose down). The skull was exposed, and a hole was drilled on the midline extending from $5 \mathrm{~mm}$ posterior to bregma to $5 \mathrm{~mm}$ posterior to lambda. The dura and sagittal sinus were ligated, transected, and reflected to allow for a midline approach to the DR with minimal blood loss.

Double- or triple-barrel glass micropipettes were used for extracellular single-unit recording of DR discharge and simultaneous peptide microinfusion (Akaoka et al., 1992). These consisted of one or two infusion pipettes (Fisher Scientific, Pittsburgh, PA) glued adjacent to a recording pipette (Friedrich and Dimmock, Millville, NJ). The recording pipette was filled with either 2\% Pontamine Sky Blue (PSB) dye in 0.5 m sodium acetate or with $1.5 \%$ neurobiotin (Vector Laboratories, Burlingame, CA) in $0.5 \mathrm{~m}$ sodium acetate. PSB-filled recording pipettes had a $2-$ to $4-\mu \mathrm{m}$ diameter tip (4-7 M $\Omega$ ), whereas neurobiotin-filled recording pipettes had a $<1-\mu \mathrm{m}$-diameter tip (16-20 M $\Omega$ ). The infusion pipettes (50- to 100 - $\mu \mathrm{m}$-diameter tip) were angled at $\sim 30-45^{\circ}$ with tips adjacent to the tip of the recording pipette but $100-125 \mu \mathrm{m}$ dorsal. These pipettes were calibrated such that a known volume could be administered $(1 \mathrm{~mm}$ displacement $=60 \mathrm{nl}$ ). The infusion pipette was filled with a solution of UII $(0.0033-1 \mathrm{mg} / \mathrm{ml})$. Triple-barrel micropipettes were used in antagonist studies. In these cases, the second infusion barrel was filled with a solution of the selective CRF-R2 antagonist antisauvagine-30 (AS-30; 1 $\mathrm{mg} / \mathrm{ml}$ ).

The micropipette was positioned between 8.7 and $9.3 \mathrm{~mm}$ posterior to bregma on midline and advanced using a hydraulic microdrive (Trent Wells Inc., Coulterville, CA); cells were typically isolated at depths between 5.0 and $6.2 \mathrm{~mm}$ from dura. Recordings were made with an intracellular amplifier in bridge mode (Axoclamp, Axon Instruments, Foster City, CA) such that current could be injected through the electrode. Signals were filtered, and a window discriminator was used to convert the occurrence of each potential into digital pulses, which were led into a computer via a CED interface (Cambridge Electronic Design, Cambridge, UK) using Spike 2 software for on-line visualization, storage, and off-line analysis.

Single-unit extracellular activity was also recorded from locus coeruleus (LC) neurons to verify that doses of the CRF-R1 antagonist anta- larmin used in this study were sufficient to block central CRF-R1 receptors. The surgical and recording techniques for single-unit LC recording and intracerebroventricular injection of oCRF were identical to those described previously (Curtis et al., 1994).

Experimental protocol. Once a single neuron was isolated, basal discharge rate was recorded until the rate was stable for at least $2 \mathrm{~min}$. UII was then microinfused by applying small pulses of pressure to the calibrated infusion pipette using a picospritzer (Parker Hannifin Corp., Fairfield, NJ) to deliver a volume of $30 \mathrm{nl}$. This required a mean of $14 \pm 1 \mathrm{sec}$. The movement of the solution through the calibrated pipette was observed as pulses were administered. The discharge rate was recorded for at least 5 min after administration of the peptide was complete. In some instances, the CRF-R2 antagonist antisauvagine-30 was administered in the same manner after a 5 min recovery period, or the CRF-R1 antagonist antalarmin $(20 \mathrm{mg} / \mathrm{kg}$, i.p.) was administered. UII administration was repeated $10 \mathrm{~min}$ after AS-30 administration or $30 \mathrm{~min}$ after antalarmin administration. In experiments involving LC recordings, antalarmin (20 $\mathrm{mg} / \mathrm{kg}$, i.p.) was administered $30 \mathrm{~min}$ before intracerebroventricular injection of oCRF ( $3 \mu \mathrm{g}$ in $3 \mu \mathrm{l}$ ), and neuronal activity was recorded for at least 12 min after CRF injection.

After the experiment, the recording site was marked by iontophoresis of PSB from the recording pipette $(-15 \mu \mathrm{A}, 15 \mathrm{~min})$, or the neuron was juxtacellularly labeled with neurobiotin, as described previously (Pinault, 1996; Schreihofer and Guyenet, 1997). For juxtacellular labeling, pulses of anodal current (200 msec, 50\% duty cycle) were delivered. The current amplitude was increased incrementally (in $0.1 \mathrm{nA}$ steps) from $0.4 \mathrm{nA}$ to a maximum of $10 \mathrm{nA}$ until cell firing became entrained. The intensity of current was adjusted to maintain entrainment without damaging the cell. No more than two cells per rat were labeled in this way. The coordinates of labeled cells were recorded to allow for accurate correspondence between histological identification and electrophysiological response. Rats remained halothane anesthetized for $1 \mathrm{hr}$ before transcardial perfusion with ice-cold $4 \%$ paraformaldehyde in $0.1 \mathrm{~m}$ phosphate buffer (PB). In cases in which PSB was iontophoresed, the brains were removed and quick-frozen in 2-methylbutane.

Histology. When PSB iontophoresis was used for histological identification, coronal $30-\mu \mathrm{m}$-thick sections were cut on a cryostat and mounted directly on Superfrost Plus slides (Fisher Scientific). These were stained with neutral red, dehydrated in a series of alcohols, cleared with xylene, and coverslipped for visualization of the PSB spot. For experiments in which oCRF was administered intracerebroventricularly to assess the effects of antalarmin on CRF-elicited LC activation, $5 \mu \mathrm{l}$ of neutral red was injected through the intracerebroventricular cannula, and the presence of dye throughout the ventricular system was used to verify the injection site.

Immunohistochemistry. When juxtacellular labeling was used to identify recorded neurons, brains were removed after perfusion, postfixed for at least $1 \mathrm{hr}$ at $4^{\circ} \mathrm{C}$, and stored in $20 \%$ sucrose solution in PB containing $0.1 \%$ sodium azide at $4^{\circ} \mathrm{C}$ for at least $24 \mathrm{hr}$. Coronal $30-\mu \mathrm{m}$-thick sections were cut on a cryostat and collected in PB. Sections were first incubated in $0.75 \% \mathrm{H}_{2} \mathrm{O}_{2}$ for $20 \mathrm{~min}$ and rinsed three times in PBS, $\mathrm{pH}$ 7.4. Sections were incubated in $\mathrm{Cy} 3$-conjugated streptavidin (1:1000; Jackson Laboratories, West Grove, PA) for $90 \mathrm{~min}$ at room temperature, rinsed, and mounted on regular glass slides so that they could be easily removed at a later time. The sections were visualized using a Leica microscope equipped with a rhodamine filter. Sections that contained neurobiotin-labeled cell bodies were removed from the slide, rinsed, and incubated in rabbit anti-5-HT antiserum (1:5000; Immunostar, Hudson, WI) in PBS containing $0.3 \%$ Triton, $0.04 \%$ bovine serum albumin (PBST-BSA), and $0.1 \%$ sodium azide for $48 \mathrm{hr}$ at $4^{\circ} \mathrm{C}$. These were rinsed with PBST-BSA and incubated in fluorescein-conjugated donkey antirabbit antiserum (1:200; Jackson Laboratories) for $90 \mathrm{~min}$ at room temperature. Sections were rinsed in PB, mounted, and coverslipped using Vectashield (Vector Laboratories). Neurobiotin and 5-HT labeling were visualized with rhodamine and fluorescein filters, respectively. Images were captured with a Hamamatsu ORCA-ER digital camera (Bridgewater, NJ) using Open Lab software (Improvision, Coventry, UK). Frames were obtained sequentially, pseudocolored, and superimposed using 
Open Lab software. Figures were assembled and adjusted for brightness and contrast in Adobe Photoshop.

Data analysis. For DR recordings, discharge rate was determined in 30 sec intervals after peptide injection and expressed as a percentage of the mean basal discharge rate determined over the $90 \mathrm{sec}$ before peptide injection. For LC recordings, discharge rate was determined for up to 9 min before oCRF injection and the following $12 \mathrm{~min}$ in $3 \mathrm{~min}$ intervals. A one-way repeated measures ANOVA was used to determine statistically significant effects of individual doses of UII. Additionally, the area under the curve described by effect as a function of time after peptide injection was calculated and compared between doses or between antagonistpretreated groups. Because it appeared that the responses of DR neurons to UII were heterogeneous, neurons were defined as being inhibited or activated on the basis of a change of at least $25 \%$ from baseline within the first $3 \mathrm{~min}$ after peptide injection. The number of neurons that were inhibited, activated, and not altered by different conditions was determined and compared by $\chi^{2}$ analysis. Data were used only if recording sites were localized within the nucleus of interest (either DR or LC).

Drugs. UII was used as a selective agonist at CRF-R2 receptors. This was on the basis of reported $K_{\mathrm{i}}$ values in cells transfected with CRF-R2 $\left(K_{\mathrm{i}}\right.$ $=0.66 \mathrm{nM})$ or CRF-R1 $\left(K_{\mathrm{i}}>100 \mathrm{nM}\right)$ receptors (Reyes et al., 2001). By comparison, $K_{\mathrm{i}}$ values for rCRF at CRF-R2 $\left(K_{\mathrm{i}}=42 \mathrm{nM}\right)$ and CRF-R1 $\left(K_{\mathrm{i}}\right.$ $=3.3 \mathrm{nM}$ ) indicate a lower degree of selectivity (Chen et al., 1993; Dautzenberg et al., 2001). CRF-UII and oCRF were diluted in water (1 mg/ $\mathrm{ml})$. Aliquots $(10 \mu \mathrm{l})$ were concentrated using a Savant Speed Vac concentrator, stored at $-70^{\circ} \mathrm{C}$, and dissolved in the appropriate volume of artificial CSF (ACSF) on the day of the experiment. Antalarmin (provided by Dr. Kenner Rice, Laboratory of Medicinal Chemistry, National Institutes of Health/National Institute of Diabetes and Digestive and Kidney Diseases, Bethesda, MD) was dissolved in a solution containing $5 \%$ ethanol and 5\% cremaphor and administered intraperitoneally (20 $\mathrm{mg} / \mathrm{kg}$ ). This dose was previously demonstrated to prevent behavioral and autonomic effects of CRF that are mediated by CRF-R1 receptors, but not CRF-R2 receptor-mediated effects (Briscoe et al., 2000; Zorrilla et al., 2002). Antisauvagine-30 (Phoenix Pharmaceuticals, Belmont, CA) was diluted in water $(1 \mathrm{mg} / \mathrm{ml})$. Aliquots $(10 \mu \mathrm{l})$ were concentrated and stored as described for urocortin II and reconstituted in ACSF $(1 \mathrm{mg} / \mathrm{ml})$ on the day of the experiment. The dose that was administered ( $30 \mathrm{ng}$ in 30 nl) was determined on the basis of previous studies using intracerebral administration in mice (Radulovic et al., 1999).

\section{Results}

\section{Dose-dependent effects of UII on DR neuronal activity}

The DR discharge rate recorded from 63 cells $(n=39$ rats) ranged from 0.5 to $7.3 \mathrm{~Hz}$ with a mean of $1.8 \pm 0.1 \mathrm{~Hz}$. Most of the recorded neurons $(55 \%)$ were within the middle of the anteriorposterior boundaries of the DR (Paxinos and Watson, 1998, Plate $52)$. A small percentage (4\%) of the neurons were just caudal to this (Paxinos and Watson, 1998, Plate 53). The remainder of the neurons $(41 \%)$ were somewhat rostral to this (Paxinos and Watson, 1998, Plates 49-51). UII had a bimodal effect on DR neuronal activity, similar to that reported previously for oCRF (Kirby et al., 2000). Microinfusion of the lower doses of UII (0.1$10.0 \mathrm{ng}$ ) produced a short onset inhibition of the majority of neurons (Fig. 1). Figure $2 A$ shows the mean time course of this response, which was statistically significant for the 0.1 and $1.0 \mathrm{ng}$ doses: $F_{(5,65)}=3.8, p<0.001$, and $F_{(12,122)}=4.3, p<0.001$, respectively. Most neurons were inhibited by 0.1 and $1.0 \mathrm{ng}$, and no neurons were activated by either dose (Fig. $2 B$ ). Microinfusion of $10 \mathrm{ng}$ of urocortin II also inhibited the majority of DR neurons (11 of 15), although the mean effect over time was not statistically significant $\left(F_{(14,153)}=1.7 ; p=0.09\right)$. Three neurons were activated by this dose of urocortin II, and one neuron was unaffected.

UII (30 ng) produced a different profile of effects, such that most of the neurons were robustly activated and the percentage of neurons that were inhibited decreased (Fig. 2 B). Figure 1 shows
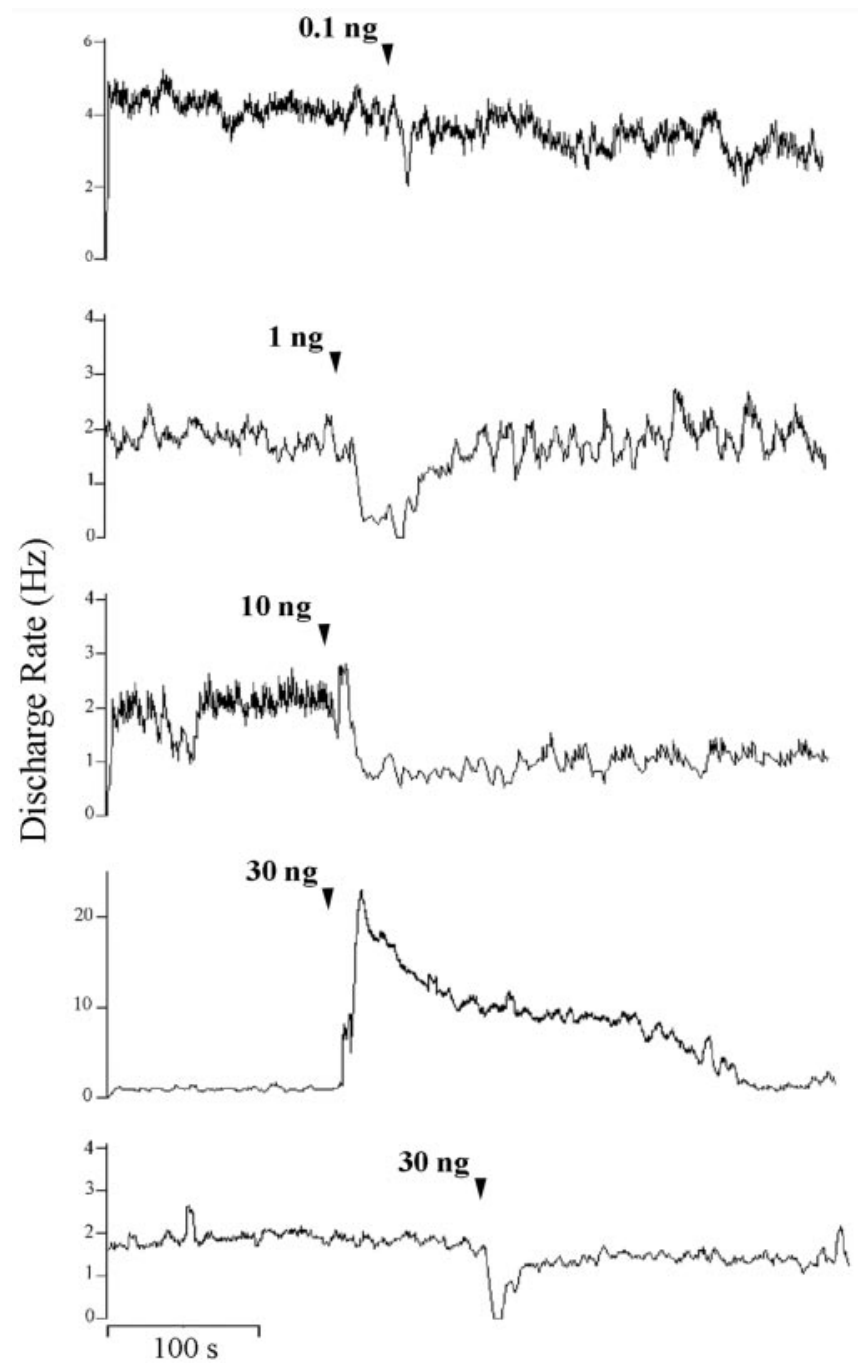

Figure 1. Representative traces of DR neuronal discharge before and after local administration of UII ( $0.1-30 \mathrm{ng})$. The ordinate indicates the discharge rate (in Hertz). Each trace represents a neuron recorded from different rats. Ull was administered as indicated by the arrowhead above the trace. Note that relatively low doses of UII (0.1-10 ng) were inhibitory. In contrast, UII $(30 \mathrm{ng})$ produced a large excitatory response in some neurons and inhibited others.

examples of excitatory and inhibitory effects of $30 \mathrm{ng}$ of UII on two different DR neurons. Of 29 DR neurons, 12 were activated, 8 were inhibited, and 9 were unaffected by $30 \mathrm{ng}$ of urocortin II. The one-way ANOVA did not reveal statistically significant effects over time $\left(F_{(28,279)}=1.3\right)$ (Fig. $\left.2 A\right)$. The data obtained with this dose were consistent with a population that was not normally distributed [Kolmogorov-Smirnov (K-S) probability $<0.001$ ].

Figure $2 B$ shows the pattern of responses that was observed with each dose of urocortin II. $\chi^{2}$ analysis revealed a dosedependent effect on the proportion of neurons exhibiting specific responses, confirming that low doses of UII were predominantly inhibitory, whereas the highest dose was more frequently excitatory (Fig. $2 B)\left(\chi^{2}(6)=21 ; p<0.002\right)$. Likewise, there was a dose-dependent effect of the area under the curve describing effect as a function of time $\left(H_{(3)}=10.5 ; p<0.02\right.$; Kruskal-Wallis ANOVA).

\section{Neurochemical content as a determinant of the response to UII}

Because the DR contains both 5-HT and non-5-HT cells, the finding that responses to $30 \mathrm{ng}$ of UII were substantially different 

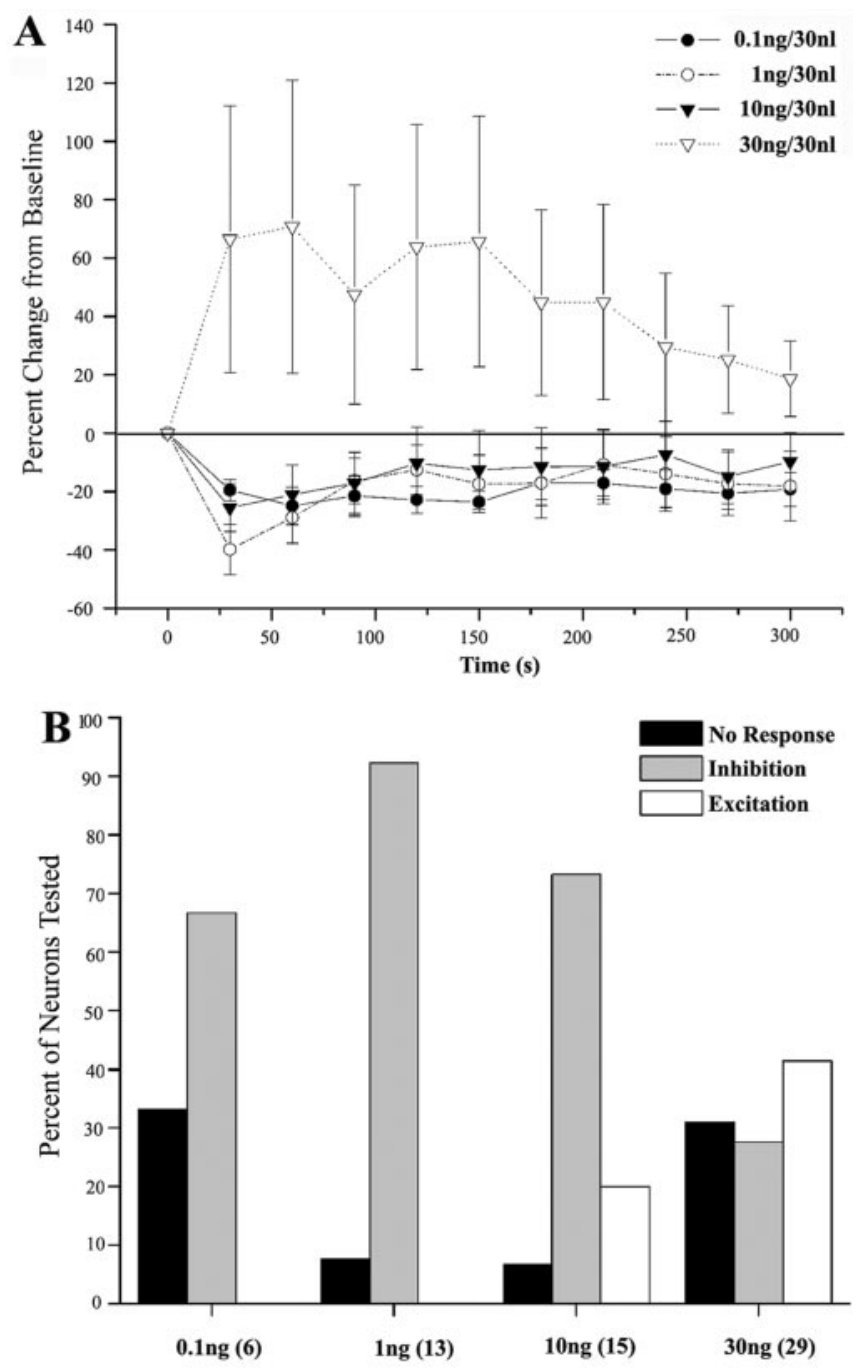

Figure 2. Quantification of the dose-dependent bimodal effects of UII. A, Mean time course of the response to different doses of UII. Each point is the mean of $6-29$ neurons, and vertical lines represent \pm SEM. One-way ANOVA revealed significant effects of time for the 0.1 and 1.0 ng doses: $F_{(5,65)}=3.8, p<0.001$ for $0.1 \mathrm{ng}$, and $F_{(12,122)}=4.3, p<0.001$ for $1.0 \mathrm{ng}$. A comparison of the area under the curve described by the effect as a function of time between different doses of UII revealed statistical significance; $H_{(3)}=10.5 ; p<0.02$; Kruskal-Wallis one-way ANOVA on ranks. $B$, Histogram indicates the percentage of neurons that were nonresponsive, inhibited, or excited by different doses of UII. The number of neurons tested is indicated in parentheses. $\chi^{2}$ analysis revealed a significant effect of dose: $\chi^{2}(6)=21 ; p<0.002$.

suggested that different neuronal populations may be targeted by this dose. Therefore, recorded neurons were juxtacellularly labeled with neurobiotin and immunohistochemically processed to determine whether they were 5-HT immunoreactive. A total of 29 neurons were successfully labeled with neurobiotin, and 16 of these neurons were 5-HT immunoreactive. Discharge rates of 5-HT and non-5-HT neurons were $1.5 \pm 0.1$ and $2.0 \pm 0.3 \mathrm{~Hz}$, respectively. Because the discharge rates of non-5-HT neurons were not normally distributed (K-S distance $=0.33 ; p<0.001$ ), means were compared using the Mann-Whitney rank sum test and did not differ $(p=0.25)$. Figure $3 A-D$ shows examples of juxtacellularly labeled neurons that were either 5-HT immunoreactive or not and their response to a low ( $0.1 \mathrm{ng}$ ) or high (30 ng) dose of UII. Here a neuron that was inhibited by UII ( $0.1 \mathrm{ng})$ was 5-HT immunoreactive (Fig. $3 A$ ), and a neuron that was unaffected by this dose was not 5 -HT immunoreactive (Fig. $3 B$ ). In contrast, a neuron that was activated by UII (30 ng) was 5 -HT immunoreactive (Fig. 3C), whereas a neuron that was inhibited by UII (30 ng) was non-5-HT immunoreactive (Fig. 3D). The effects of UII administration on 5-HT versus non-5-HT DR neurons are summarized in Figure 4. In general, low doses of UII (0.1-10 ng), which inhibited the majority of neurons (Fig. 2 B), inhibited 5-HT neurons and had mixed effects on non-5-HT neurons. Notably, 5-HT neurons were never activated by these doses of UII. An opposite profile of effects was observed with 30 ng of UII. Most of the 5-HT neurons were activated by $30 \mathrm{ng}$ of UII, and inhibition of 5-HT neurons was never observed. In contrast, most non-5-HT neurons were inhibited by 30 ng of UII. $\chi^{2}$ analysis revealed dose-dependent effects for 5-HT neurons $\left(\chi^{2}\right.$ (2) $=12.9 ; p=0.002$ ).

\section{Sensitivity to CRF-R1 and CRF-R2 antagonists}

Administration of the selective CRF-R2 antagonist antisauvagine-30 $10 \mathrm{~min}$ before UII (10 ng) attenuated the inhibition produced by this dose and was sufficient to reverse the inhibition when administered after this dose (Fig. 5A1). Figure $5 B$ shows that most of the neurons were not affected by UII ( 10 $\mathrm{ng}$ ) in seven rats pretreated with antisauvagine-30, in contrast to cases in which the antagonist was not administered $\left(\chi^{2}(2)=\right.$ $10.5 ; p=0.005)$. Unlike antisauvagine-30, the selective CRF-R1 antagonist antalarmin did not alter the inhibitory response to UII (10 ng) in any neuron tested $(n=4)$ (Fig. 5A2). This dose of antalarmin antagonized a maximally effective dose of CRF on LC activity. LC discharge after CRF ( $3 \mu$ g, i.c.v.) was increased by $74 \pm 8 \%$ in control rats $(n=9)$ and by $29 \pm 8 \%$ in rats pretreated with antalarmin $(n=7 ; p<0.002$; Student's unpaired $t$ test).

When UII (30 ng) was administered after antisauvagine-30, the percentage of neurons that were excited was substantially reduced (Fig. 5B). Only 1 neuron of 10 was activated (by a magnitude of $70 \%$ above baseline); however, the percentage of neurons inhibited by this dose of UII was not altered (Fig. 5B). The difference in response to UII ( $30 \mathrm{ng}$ ) is reflected in the area under the curve defined by effect over time (Fig. 5C), which was statistically significant ( $p<0.05$; Mann-Whitney rank sum test).

\section{Discussion}

The present study is the first to describe the effects of selective CRF-R2 receptor activation on DR neuronal activity. Direct injection of UII into the DR had a dose-dependent bimodal effect on DR neuronal activity. Low doses of UII inhibited most neurons and increasing the dose of UII activated a population of DR neurons. Neurochemical identification revealed that 5-HT neurons were inhibited by low doses of UII and activated by the highest dose. The finding that this higher dose of UII was also primarily inhibitory to non-5-HT neurons suggests that activation of 5-HT neurons by this dose could result from disinhibition. Thus, selective CRF-R2 activation in the DR can regulate the tone of the DR-5-HT system, and therefore its functional consequences, in opposing directions depending on the level of endogenous ligand. This has important implications for how the system functions during specific challenges and for pharmacological manipulation of this system in clinical disorders.

\section{Technical considerations}

Juxtacellular labeling combined with unit recording has been used to correlate response characteristics with cellular morphology and neurochemical identity in several brain regions (Pinault, 1996; Schreihofer and Guyenet, 1997). The interpretations of these studies rely on the assumption that the recorded neuron is 


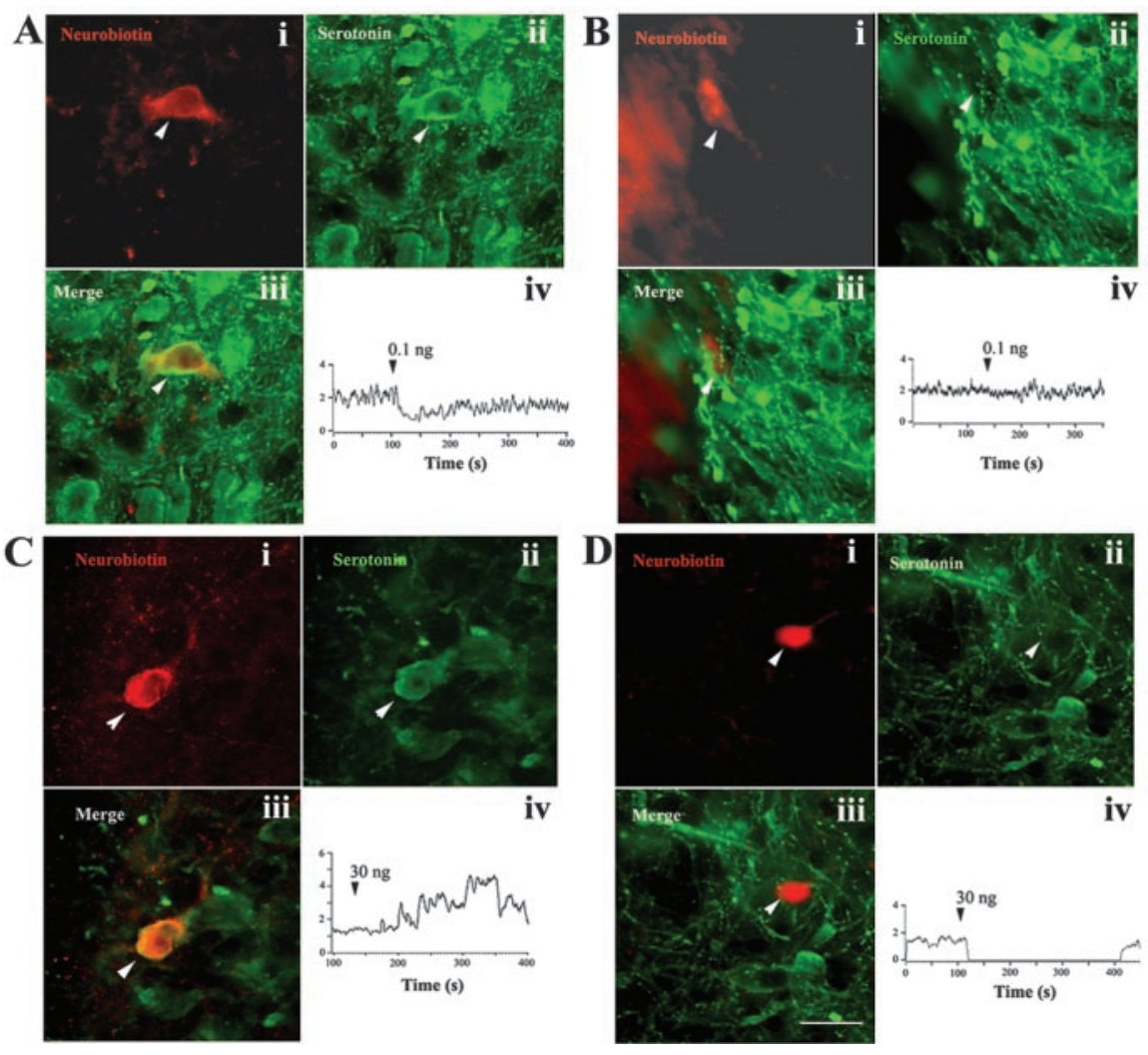

Figure 3. Neurochemical identification of neurons that were differentially affected by a low and high dose of UII. $A-D$, Shown are four neurons (arrowheads) that were labeled with neurobiotin ( $i$ ) and the responses of the neurons to 0.1 (Aiv, Biv) or $30 \mathrm{ng}$ (Civ, Div) Ull. Aii-Dii show 5-HT immunoreactivity in the same section as Ai-Di, respectively. Aiii-Diii show the merged images. In $A$ and $C$, the neurobiotin-labeled neurons were also 5 -HT immunoreactive as indicated by the yellow-orange color in the merged image. In $B$ and $D$, the neurons were not 5-HT immunoreactive. Scale bar, $20 \mu \mathrm{m}$.

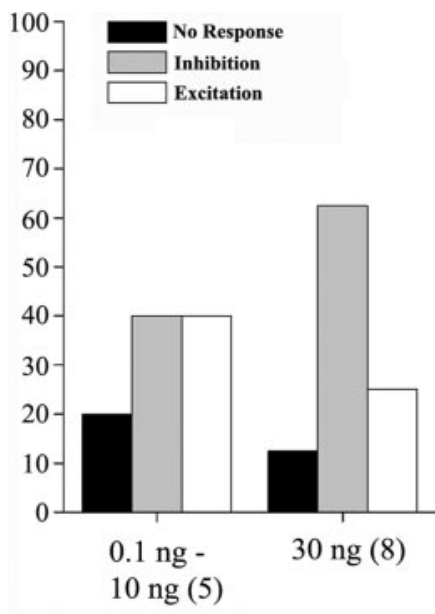

Non - 5 - HT

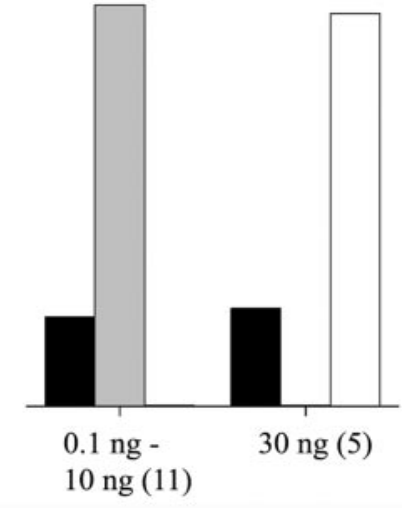

5-HT
Figure 4. Histogram indicating the percentage of non-5-HT and 5-HT neurons that were nonresponsive, inhibited, or activated by relatively low doses of UII ( $0.1-10 \mathrm{ng})$ or a high dose of UII (30 ng). Numbers in parentheses indicate the number of neurons tested. $\chi^{2}$ analyses revealed a statistically significant effect of dose for 5 -HT neurons $\left(\chi^{2}(2)=12.9 ; p=0.002\right)$.

that which exhibits labeling. This is supported by studies showing that extracellular current ejection does not result in cellular labeling (Pinault, 1996; Schreihofer and Guyenet, 1997). In the present study, current ejection labeled one neuron, and careful recording of dorsal-ventral positions revealed that labeled neurons were localized in the corresponding site and not distal sites, as would be predicted if labeling had been caused by retrograde transport.

The interpretations of the present results rely on the selectivity of UII at the CRF-R2 receptor subtype. This is supported by previous binding and functional data (Hsu and Hsueh, 2001; Reyes et al., 2001). Consistent with this, in the present study, inhibition produced by UII (10 ng) was attenuated by the CRF-R2 antagonist antisauvagine-30 but not by the CRF-R1 antagonist antalarmin at doses that were sufficient to attenuate LC activation mediated by oCRF. Antisauvagine- 30 also decreased the percentage of neurons that were activated by UII ( $30 \mathrm{ng}$ ) and the area under the curve of the response. Although the percentage of neurons that were inhibited by this higher dose of UII was not altered by antisauvagine-30, this would be predicted if the curve were shifted to the right; i.e., the effects of a high dose of UII would be comparable with those of a lower dose.

\section{Relationship to previous studies}

The prominent localization of CRF fibers (Valentino et al., 2001), binding sites (Rominger et al., 1998), and receptor mRNA (Chalmers et al., 1995) within the DR provide evidence that this nucleus is targeted by endogenous CRF. Evidence from DR neuronal recordings and microdialysis studies measuring 5-HT extracellular levels in DR forebrain targets indicate that CRF impacts on this system; however, these studies have yielded conflicting results regarding the effects of CRF. For example, in slice preparations in vitro, DR neurons were activated by $\mathrm{CCRF}$ and oCRF (Lowry et al., 2000). In contrast, low doses of oCRF inhibited DR discharge in vivo and 5-HT extracellular levels in forebrain targets of the DR (Price et al., 1998; Kirby et al., 2000; Price and Lucki, 2001). Several characteristics of CRF-DR interactions can account for these discordant responses. CRF innervation of the DR is not uniform but rather topographically organized. Moreover, the types of interactions formed by CRF-containing axon terminals with other cellular processes in the DR vary between different subregions of the DR (Valentino et al., 2001). Thus, CRF axon terminals form synapses with dendrites more frequently in the dorsolateral DR than in the ventromedial DR, where appositions with other axons are more prominent. Because of these topographical differences, CRF may have distinct effects depending on the DR subregion or forebrain target that is examined. In this regard, excitatory effects of CRF in vitro were observed in the caudal DR (Lowry et al., 2000). Inhibition of the DR-5-HT system by swim stress has been linked to CRF actions on GABA neurons in the dorsolateral DR (Roche et al., 2003). The existence of multiple CRF receptors in the DR further adds to the potential for complex effects. Although it is recognized that CRF-R2 receptors are more prevalent than CRF-R1 in the DR (Chalmers et al., 1995), the precise distribution of different receptor subtypes throughout the DR or the neuronal types that express CRF-R1 versus CRF-R2 is unknown. An individual neuron expressing both receptor subtypes may have opposing responses to a CRF 
analog depending on its relative selectivity and available concentration. Finally, the same receptor may be present on different but interacting DR neurons. To better clarify CRF actions on DR neurons, the present study characterized the effects of selective activation of the more prevalent CRF receptor subtype, CRF-R2.

The effects of UII resembled those reported for oCRF (Kirby et al., 2000), which can interact with both CRF receptor subtypes but is more selective at CRF-R1 receptors. Both peptides decreased DR discharge at low doses, and this effect diminished with higher doses (Kirby et al., 2000); however, the inhibition produced by the two peptides was distinct. In the present study, inhibition produced by UII was more robust and of a shorter latency than the previously reported effects of oCRF. Importantly, oCRF and UII were differentially sensitive to CRF-R1 versus CRF-R2 antagonists, respectively. Although DR neurons that were responsive to oCRF were not neurochemically characterized, anatomic evidence suggests that activation of CRF-R1 on GABA neurons in the dorsolateral DR contributes to stress-induced inhibition of this system (Roche et al., 2003).

The use of juxtacellular labeling combined with immunohistochemistry in the present study was critical for distinguishing dual mechanisms of action of UII. The results provide physiological evidence for the existence of CRF-R2 receptors on 5-HT and non-5-HT DR neurons and that interaction with these has opposing consequences on 5-HT activity. The finding that excitation of 5-HT neurons was apparent only with the highest doses of UII may be explained if this effect requires a greater degree of receptor occupancy compared with the direct inhibition of 5-HT neurons. For example, if 5-HT neurons have a higher density of receptors and a smaller percentage of the receptors needs to be occupied to produce inhibition (i.e., there are spare receptors), then low doses of UII would only inhibit 5-HT neurons. Receptors mediating the excitatory response (presumably inhibition of non-5-HT neurons that synapse with 5-HT neurons) may become sufficiently occupied only at higher doses of UII. An alternative explanation for the present results is that the two actions of UII are mediated by distinct receptors on 5-HT neurons. Although this possibility cannot be ruled out, it is considered less likely given the pharmacological evidence that UII is selective for CRF-R2 receptors and that both inhibition by the low dose of UII and excitation by the high dose of UII are sensitive to a CRF-R2 antagonist.

It is of interest to determine the neurochemical phenotype of non-5-HT neurons that are inhibited by UII (30 ng) because these neurons may provide an additional pharmacological target for manipulating the system. Although there are multiple inhibitory neuromodulators in the DR, GABA is a likely candidate because GABA-containing neurons are present and are contacted by CRF axon terminals in the DR (Waselus et al., 2003). This would be of interest given previous studies suggesting that DR5-HT neurons are inhibited by activation of CRF-R1 receptors on
GABA neurons (Roche et al., 2003). If the UII-elicited activation of DR-5-HT neurons occurs through inhibition of GABA neurons, it would suggest that GABA neurons express both CRF-R1 and CRF-R2 receptors, which have opposing effects, i.e., activation of GABA neurons via CRF-R1 and inhibition via CRF-R2.

\section{Functional implications}

The dual effects of UII on DR-5-HT neuronal activity imply that activation of CRF-R2 receptors in the DR can regulate this system in a dynamic manner, having opposing effects depending on the concentration of agonist available to receptors. Stimuli that release relatively low levels of the endogenous agonist or submaximal doses of exogenously administered agonist would be predicted to inhibit the DR-5-HT system. Inhibition of this system has been implicated in promoting active responses to challenges such as swim stress (Roche et al., 2003). In contrast, stimuli that release high levels of endogenous agonist or doses of exogenous agonist that are sufficient to saturate receptors would be predicted to activate this system. Recently, excitation of DR-5-HT neurons (as evidenced by c-fos immunoreactivity) has been proposed to occur during uncontrollable shock as a result of CRF-R2 activation. This effect has been implicated in deficits in active escape behavior (Hammack et al., 2003). Thus, the wide range regulation of the DR-5-HT system by CRF-R2 activation may allow for the facilitation of multiple behavioral strategies to a challenge, with active responses being promoted by inhibition and passive responses being promoted by excitation. Likewise, the findings suggest mechanisms for modulating behavior by ti- 
trating the dose of specific CRF analogs. This has important implications for pharmacotherapy of affective disorders.

\section{References}

Adell A, Casanovas JM, Artigas F (1997) Comparative study in the rat of the actions of different types of stress on the release of 5-HT in raphe nuclei and forebrain areas. Neuropharmacology 36:735-741.

Akaoka H, Saunier C-F, Chergui K, Charlety P, Buda M, Chouvet G (1992) Combining in vivo volume-controlled pressure microejection with extracellular unit recording. J Neurosci Methods 42:119-128.

Briscoe RJ, Cabrera CL, Baird TJ, Rice KC, Woods JH (2000) Antalarmin blockade of corticotropin-releasing hormone-induced hypertension in rats. Brain Res 881:204-207.

Chalmers DT, Lovenberg TW, De Souza EB (1995) Localization of novel corticotropin-releasing factor receptor (CRF2) mRNA expression to specific subcortical nuclei in rat brain: comparison with CRF1 receptor mRNA expression. J Neurosci 15:6340-6350.

Chen R, Lewis KA, Perrin MH, Vale WW (1993) Expression cloning of a human corticotropin-releasing factor receptor. Proc Natl Acad Sci USA 90:8967-8971.

Curtis AL, Grigoradis D, Page ME, Rivier J, Valentino RJ (1994) Pharmacological comparison of two corticotropin-releasing factor antagonists: in vivo and in vitro studies. J Pharmacol Exp Ther 268:359-365.

Dautzenberg FM, Kilpatrick GJ, Hauger RL, Moreau J-L (2001) Molecular biology of the CRH receptors-in the mood. Peptides 22:753-760.

Grahn RE, Maswood S, McQueen MB, Watkins LR, Maier SF (1999) Activation of serotonin-immunoreactive cells in the dorsal raphe nucleus in rats exposed to an uncontrollable stressor. Brain Res 826:35-43.

Hammack SE, Richey KJ, Schmid MJ, LoPresti ML, Watkins LR, Maier SF (2002) The role of corticotropin-releasing hormone in the dorsal raphe nucleus in mediating the behavioral consequences of uncontrollable stress. J Neurosci 22:1020-1026.

Hammack SE, Schmid MJ, LoPresti ML, Der-Avakian A, Pellymounter MA, Foster AC, Watkins LR, Maier SF (2003) Corticotropin-releasing hormone type 2 receptors in the dorsal raphe nucleus mediate the behavioral consequences of uncontrollable stress. J Neurosci 23:1019-1025.

Hsu SY, Hsueh AJW (2001) Human stresscopin and stresscopin-related peptide are selective ligands for the corticotropin-releasing hormone receptor. Nat Med 7:605-611.

Jacobs BL, Azmitia EC (1992) Structure and function of the brain serotonin system. Physiol Rev 72:165-228.

Kirby LG, Allen AR, Lucki I (1995) Regional differences in the effects of forced swimming on extracellular levels of 5-hydroxytryptamine and 5-hydroxyindoleacetic acid. Brain Res 682:189-196.

Kirby LG, Chou-Green JM, Davis K, Lucki I (1997) The effects of different stressors on extracellular 5-hydroxytryptamine and 5-hydroxyindoleacetic acid. Brain Res 760:218-230.

Kirby LG, Rice K, Valentino RJ (2000) Effects of corticotropin-releasing factor on neuronal activity in the serotonergic dorsal raphe nucleus. Neuropsychopharmacology 22:148-162.

Linthorst ACE, Flachskamm C, Hopkins SJ, Hoadley ME, Labeur MS, Holsboer F, Reul JMHM (1997) Long-term intracerebroventricular infusion of corticotropin-releasing hormone alters neuroendocrine, neurochemi$\mathrm{cal}$, autonomic, behavioral, and cytokine responses to a systemic inflammatory challenge. J Neurosci 17:4448-4460.

Lowry CA, Rodda JE, Lightman SL, Ingram CD (2000) Corticotropinreleasing factor increases in vitro firing rates of serotonergic neurons in the dorsal raphe nucleus: evidence for activation of a topographically organized mesolimbocortical serotonergic system. J Neurosci 20:7728-7736.

Mann JJ (1999) Role of the serotonergic system in the pathogenesis of major depression and suicidal behavior. Neuropsychopharmacology 21:99S-105S.

Molliver ME (1987) Serotonergic neuronal systems: what their anatomic organization tells us about function. J Clin Psychopharmacol 7:3S-23S.

Nutt D (2002) The neuropharmacology of serotonin and noradrenaline in depression. Int Clin Psychopharmacol 17 [Suppl]1:S1-S12.

Paxinos G, Watson C (1998) The rat brain in stereotaxic coordinates. North Ryde, UK: Academic.

Pinault D (1996) A novel single-cell staining procedure performed in vivo under electrophysiological control: morpho-functional features of juxtacellularly labeled thalamic cells and other central neurons with biocytin or neurobiotin. J Neurosci Methods 65:113-136.

Price ML, Lucki I (2001) Regulation of serotonin release in the lateral septum and striatum by corticotropin-releasing factor. J Neurosci 21:2833-2841.

Price ML, Curtis AL, Kirby LG, Valentino RJ, Lucki I (1998) Effects of corticotropin-releasing factor on brain serotonergic activity. Neuropsychopharmacology 18:492-502.

Price ML, Kirby LG, Valentino RJ, Lucki I (2002) Evidence for corticotropin-releasing factor regulation of serotonin in the lateral septum during acute swim stress: adaptation produced by repeated swim. Psychopharmacology 162:406-414.

Radulovic J, Ruhmann A, Liepold T, Spiess J (1999) Modulation of learning and anxiety by corticotropin-releasing factor (CRF) and stress: differential roles of CRF receptors 1 and 2. J Neurosci 19:5016-5025.

Reyes TM, Lewis K, Perrin MH, Kunitake KS, Vaughan J, Arias CA, Hogenesch JB, Gulyas J, Rivier J, Vale WW, Sawchenko PE (2001) Urocortin II: a member of the corticotropin-releasing factor (CRF) neuropeptide family that is selectively bound by type 2 CRF receptors. Proc Natl Acad Sci USA 98:2843-2848.

Roche M, Commons KG, Peoples A, Valentino RJ (2003) Circuitry underlying regulation of the serotonergic system by swim stress. J Neurosci 23:970-977.

Rominger DH, Rominger CM, Fitzgerald LW, Grzanna R, Largent BL, Zaczek $\mathrm{R}$ (1998) $\left[{ }^{125} \mathrm{I}\right]$ sauvagine binding to $\mathrm{CRH} 2$ receptors: membrane homogenate and autoradiographic studies. J Pharmacol Exp Ther 286:459-468.

Rueter LE, Fornal CA, Jacobs BL (1997) A critical review of 5-HT brain microdialysis and behavior. Rev Neurosci 8:117-137.

Schreihofer AM, Guyenet PG (1997) Identification of C1 presympathetic neurons in rat rostral ventrolateral medulla by juxtacellular labeling in vivo. J Comp Neurol 387:524-536.

Valentino RJ, Liouterman L, Van Bockstaele EJ (2001) Evidence for regional heterogeneity in corticotropin-releasing factor interactions in the dorsal raphe nucleus. J Comp Neurol 435:450-463.

Waselus M, Valentino RJ, Van Bockstaele EJ (2003) Synaptic interactions between axon terminals containing corticotropin-releasing factor (CRF) and somatodendritic processes containing serotonin in the rat dorsal raphe nucleus (DRN). Soc Neurosci Abstr 712.4.

Zorrilla EP, Valdez GR, Nozulak J, Koob GF, Markou A (2002) Effects of antalarmin, a CRF type 1 receptor antagonist, on anxiety-like behavior and motor activation in the rat. Brain Res 952:188-199. 